\title{
Coprecipitation: An excellent tool for the synthesis of supported metal catalysts - From the understanding of the well known recipes to new materials
}

\author{
$\underline{\text { M. Behrens }}{ }^{1,2 *}$ \\ ${ }^{1}$ Fritz-Haber-Institut der Max-Planck-Gesellschaft. Department of Inorganic Chemistry. \\ Faradayweg 4-6, 14195 Berlin, Germany \\ 2 University of Duisburg-Essen, Faculty of Chemistry and Center for Nanointegration \\ Duisburg-Essen (CENIDE), Universitätsstr. 7, 45141 Essen, Germany \\ (*) malte.behrens@uni-due.de
}

Keywords: Co-precipitation, precursor chemistry, supported metal nanoparticles, $\mathrm{Cu} / \mathrm{ZnO}$

\begin{abstract}
:
Constant-pH co-precipitation is a standard synthesis technique for catalyst precursors. The general steps of this synthesis route are described in this work using the successfully applied industrial synthesis of the $\mathrm{Cu} / \mathrm{ZnO} /\left(\mathrm{Al}_{2} \mathrm{O}_{3}\right)$ catalyst for methanol synthesis as an example. Therein, co-precipitation leads to well-defined and crystalline precursor compound with a mixed cationic lattice that contains all metal species of the final catalyst. The anions are thermally decomposed to give the mixed oxides and the noblest component, in this current case copper, finally segregates on a nano-metric level to yield supported and uniform metal nanoparticles. Recent examples of the application of this synthesis concept for supported catalysts are reported with an emphasis on the layered double hydroxide precursor (Cu,Zn,Al; Ni,Mg,Al; Pd,Mg,Al; Pd,Mg,Ga). This precursor material is very versatile and can lead to highly loaded base metal as well as to mono- and bi-metallic highly dispersed noble metal catalysts.
\end{abstract}

Keywords: Catalyst synthesis, Co-precipitation, $\mathrm{Cu} / \mathrm{ZnO}$, Layered double hydroxide 


\section{Introduction:}

Constant-pH co-precipitation is a standard synthesis technique for catalyst precursors [1] and referred to as the method of low supersaturation [2]. By proper adjustment of the precipitation parameters the homogeneous distribution of different metal cations in a mixed solution can be carried over to a multinary catalyst precursor by rapid solidification. Contrarily to the also commonly used impregnation methods for preformed supports, these materials contain the precursor species for the support and for the active components in the same material [3]. Highly dispersed, well inter-mixed and uniform supported metal/oxide catalysts can be obtained from such precursors by decomposition (typically calcination) and/or reduction. However, the chemistry behind the many synthesis steps and their interplay are complex and involved. For applied systems, the empirical synthesis optimization is often far more advanced than the exact knowledge of the under-lying chemistry. Thus, the evolution of many applied catalyst syntheses is usually a continuous long-term process that to a large extent is based on the experience of the manufacturer and their accumulated knowledge often leads to complex recipes. This complexity is sometimes generalized as the "black magic" of catalyst synthesis.

In this situation, the retrospective investigation of a known industrially applied synthesis procedure is an ideal starting point for reconstructing the chemistry of catalyst synthesis. One can be sure that the critical details of all unit operations have been tested for relevance and are directly imperative for the best final result: a highly active, selective and stable material suitable for industrial application. The goal of such studies thus must be to upgrade empirical synthesis parameter-function relationships to synthesis parameter-structure-function relationships that allows for an understanding and hopefully a more rational further optimization of the catalyst.

A prominent example is the co-precipitation of mixed $\mathrm{Cu}, \mathrm{Zn}, \mathrm{Al}$ hydroxycarbonates as precursor material for $\mathrm{Cu} / \mathrm{ZnO} / \mathrm{Al}_{2} \mathrm{O}_{3}$ catalysts which are employed for the industrial synthesis of methanol [4-6]. Herein, the recent progress that has been made in analyzing and understanding the well-documented industrial synthesis of this important catalyst is briefly reviewed. For a more detailed treatment, the reader is referred to recent reviews [7-9]. The key steps of the synthesis recipe of this particular catalyst and the chemical concept behind the "black magic" are identified, generalized and transferred to other catalyst systems. Herein, it is shown how the lessons learned from the industrial 
recipe can be applied to synthesize new materials through co-precipitation of different precursor compound in various catalyst systems. This work reviews our recent results obtained on $\mathrm{Cu} / \mathrm{ZnO}$-based catalysts [10-13] as well as supported Pd [14], intermetallic $\mathrm{Pd}_{2} \mathrm{Ga}$ [15-17] and $\mathrm{Ni}$ [18] catalysts with a focus on co-precipitated layered double hydroxide (LDH) precursors.

\section{Results \& Discussion:}

\subsection{Synthesis of technical methanol synthesis catalysts}

$\mathrm{Cu} / \mathrm{ZnO}$-based catalysts are industrially employed in methanol synthesis from syngas. The role of $\mathrm{Cu}$ defects and disorder [19-20] and of the "synergetic" role of $\mathrm{ZnO}$ [21-22], which exceeds the function of a mere physical stabilizer are vividly debated since many years, but beyond the scope of the present paper. The synthesis of $\left(\mathrm{Al}_{2} \mathrm{O}_{3}\right.$-promoted) $\mathrm{Cu} / \mathrm{ZnO}$ catalyst is analyzed here assuming that the copper nanoparticles must fulfill three requirements for high catalytic performance [23]: 1.) expose a large copper surface area $\left(S A_{C u}\right), 2$.) contain surface defects and, 3.) exhibit many reactive ("synergetic") interfaces to $\mathrm{ZnO}$. These requirements are elegantly realized by the nanostructured and porous $\mathrm{Cu} / \mathrm{ZnO}$ arrangement shown in the TEM image in Figure 1 that results from the industrial synthesis recipe. The $\mathrm{Al}_{2} \mathrm{O}_{3}$ promoter is usually added in low amounts to increase the stability of the catalyst, not as a classical alumina support. Preparation of this unique, but fragile microstructure requires a homogeneous and maximized intermixing of the $\mathrm{Cu}$ and $\mathrm{Zn}$ species in order to generate and stabilize the alternating arrangement of small $\mathrm{Cu}$ and $\mathrm{ZnO}$ nanoparticles. Thus, the main goal of this catalyst synthesis is to carry over and maintain to a maximal extent the perfectly homogeneous cation distribution in the starting mixed solution to the final catalyst. 


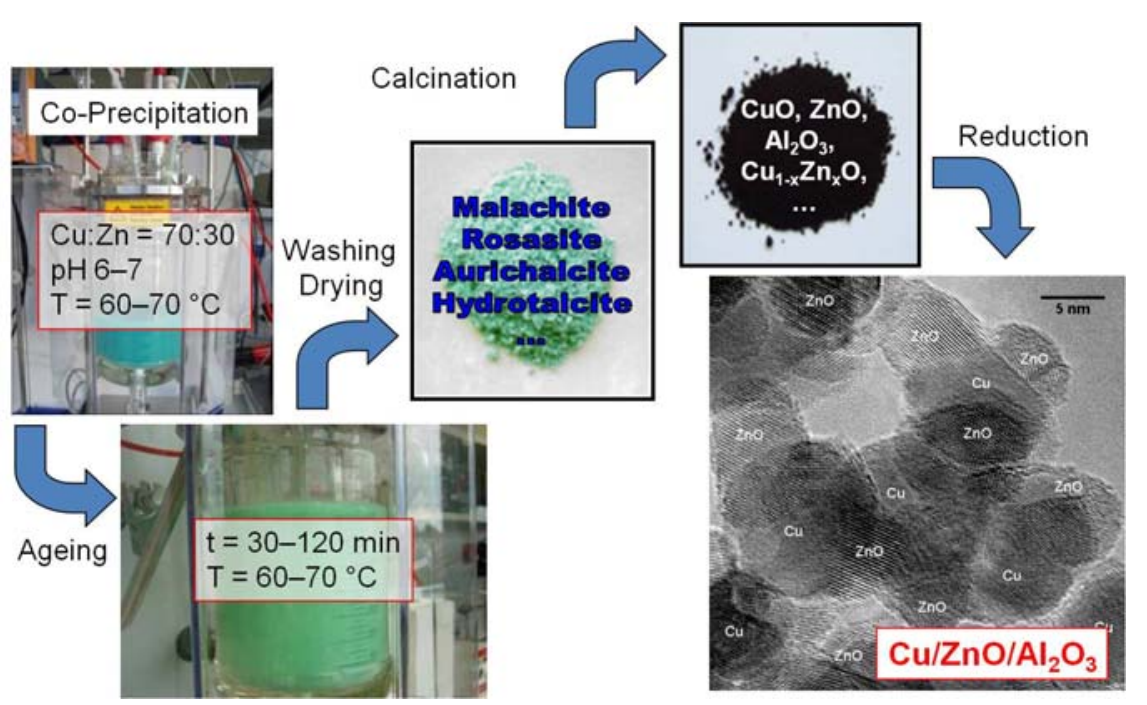

Figure 1: Schematic representation of the major steps of the ICI recipe for $\mathrm{Cu} / \mathrm{ZnO}$ catalyst synthesis . Favorable conditions that lead to high-performance catalysts are indicated in the Figure (taken from [7]).

In case of the methanol synthesis catalyst, a multistep synthesis route towards $\mathrm{Cu} / \mathrm{ZnO}$ catalysts introduced by ICI in the 1960s achieves this in a very efficient manner [4]. It is schematically shown in Figure 1 and it comprises co-precipitation [24] and ageing [2526] of a mixed $\mathrm{Cu}, \mathrm{Zn},(\mathrm{Al})$ hydroxy-carbonate precursor material [27], thermal decomposition yielding an intimate mixture of the oxides and finally activation of the catalyst by reduction of the $\mathrm{Cu}$ component [28]. The major trick of this synthesis is that under beneficial conditions the co-precipitated precursor material can be synthesized as a single homogeneous and well-defined precursor phase, zincian malachite $(\mathrm{Cu}, \mathrm{Zn})_{2}(\mathrm{OH})_{2} \mathrm{CO}_{3}$, with a mixed cationic sub-lattice that contains all components of the catalyst and can even accommodate small amounts of the $\mathrm{Al}^{3+}$ promoter [29] in a solid solution. This perfect distribution leads to an effective dilution of the active $\mathrm{Cu}$ component and is the basis for a successful nano-structuring of the precursor upon decomposition into $\mathrm{CuO} / \mathrm{ZnO}$ and for the high $\mathrm{Cu} / \mathrm{ZnO}$-interdispersion in the final reduced catalyst. This concept is schematically shown in Figure 2. Considering the synthesis of a maximally substituted and single phase zincian malachite precursor material as the primary goal of the early synthesis steps, many details of the synthesis recipe and parameters like $\mathrm{Cu}: \mathrm{Zn}$ ratio, $\mathrm{pH}$ and temperature during precipitation and ageing can indeed be understood [7, 24, 26].

In turn, these considerations provide a general guide for the synthesis of catalysts in other systems or through other precursor phase: To obtain uniform and highly 
interdispersed materials one should seek synthesis parameters that favor the crystallization of a mixed cationic lattice of all components of the catalyst with thermolabile anions like hydroxide, carbonate, formate, oxalate, formate, acetate, etc. Thereby, the substitution should be such that a maximal mixing of the components can be achieved while segregation of other phases during precursor synthesis is avoided.

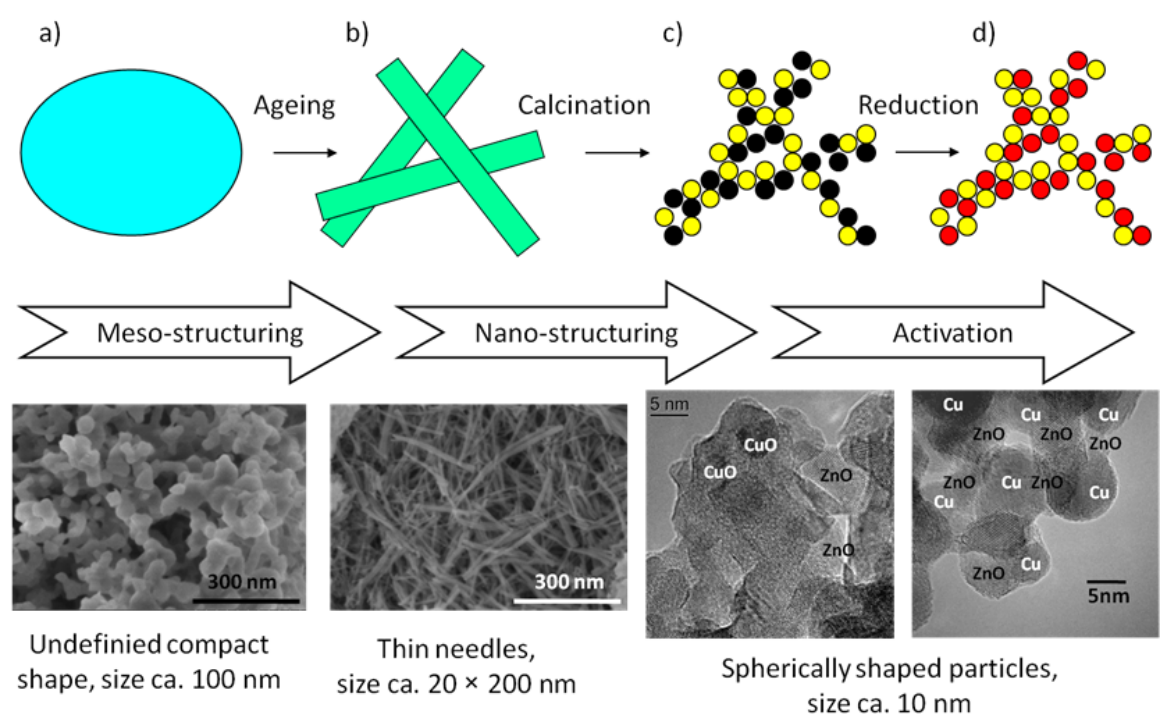

Fig. 2: Schematic representation and electron microscopy images of the microstructural evolution of an industrial $\mathrm{Cu} / \mathrm{ZnO}$ catalyst synthesized by the recipe shown in Figure 1. The co-precipitate (a) crystallizes yielding zincian malachite needles (b). During calcination the individual needles decompose into nanostructured $\mathrm{CuO} / \mathrm{ZnO}$ (c). Finally, the $\mathrm{CuO}$ component is reduced in hydrogen yielding the active state of the catalyst with a unique microstructure exhibiting high porosity and high $\mathrm{Cu}$ dispersion (taken from [7])

\subsection{Alternative precursors for new $\mathrm{Cu} / \mathrm{ZnO}$-based catalysts}

This concept that the solid state chemistry of the precursor determines the success of the catalyst synthesis can be used to explore other mixed $\mathrm{Cu}, \mathrm{Zn}$ precursor compounds than zincian malachite. For example, the principles shown in Figure 2 have been transferred to a mixed $\mathrm{Cu}, \mathrm{Zn}$ basic formate system, $\left(\mathrm{Cu}_{1-\mathrm{x}} \mathrm{Zn}_{\mathrm{x}}\right)_{2}(\mathrm{OH})_{3} \mathrm{HCO}_{2}$ [10]. After determining the proper co-precipitation conditions by means of titration experiments, a series of solid solutions with varying $x$ was prepared and structurally characterized. The system showed interesting parallels with the zincian malachite route. Similar to the 
malachite case, an anisotropic change of the unit cell parameters was observed as a function of $\mathrm{Zn}$ content that allowed finding a critical composition at $x=0.21$ beyond which segregation of by-phases was detected. Needle-like particles have been obtained as shown in Figure 3a. The successful nano-structuring of this homogeneous precursor compound upon thermal decomposition and the generation of pores can be seen in Figure $3 \mathrm{~b}$ showing the $\mathrm{CuO} / \mathrm{ZnO}$ pre-catalyst calcined in oxygen at $200{ }^{\circ} \mathrm{C}$. The absolute performance of this novel type of $\mathrm{Cu} / \mathrm{ZnO}$ catalysts was comparable to a binary zincian malachite derived benchmark of the same composition, while the promoted industrial catalysts still performed significantly better [10].
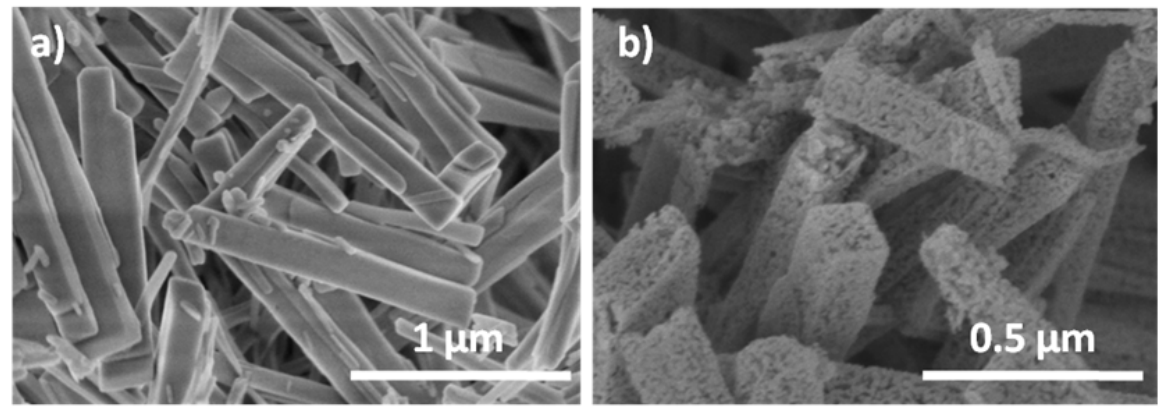

Fig. 3: Scanning electron micrographs of the $\left(\mathrm{Cu}_{1-\mathrm{x}} \mathrm{Zn}_{\mathrm{x}}\right)_{2}(\mathrm{OH})_{3} \mathrm{HCO}_{2}$ needles $(\mathrm{Cu}: \mathrm{Zn}=$ 78:22) before (a) and after (b) calcination in $\mathrm{O}_{2}$ at $200^{\circ} \mathrm{C}$ (taken from [7])

Another example, well-known in catalyst synthesis science, are layered double hydroxide ( $\mathrm{LDH})$ materials, $\mathrm{M}_{\mathrm{x}}^{\mathrm{II}} \mathrm{M}^{\mathrm{III}}{ }_{1-\mathrm{x}}(\mathrm{OH})_{2}\left(\mathrm{CO}_{3}\right)_{\mathrm{x} / 2} \cdot m \mathrm{H}_{2} \mathrm{O}$. These materials crystallize in a layered structure derived from the mineral brucite, $\mathrm{Mg}(\mathrm{OH})_{2}$. The metal cations are coordinated by six $\mathrm{OH}$ groups forming layers of edge-sharing octahedra. In case of LDH, some trivalent cations are also present within these layers and the resulting positive excess charge is compensated by inter-layer anions, typically carbonate (Fig. 4a). LDHs offer a wide substitution chemistry on the $\mathrm{M}^{\mathrm{II}}$ and $\mathrm{M}^{\mathrm{III}}$ positions including $\mathrm{Cu}, \mathrm{Zn}$ and $\mathrm{Al}$. All three metal species share the six fold coordinated sites in a layered structure, which is composed of edge-sharing octahedra. Thus, they are evenly distributed on an atomic level within a single phase. Hence, formation of catalysts of a homogeneous microstructure with high dispersion of the metal species and enhanced metal-oxide interaction can be expected after reduction. The application of LDH precursors for catalysis has been comprehensively reviewed [2] and many examples can be found in the literature. 
Synthesis of $\mathrm{Cu}, \mathrm{Zn}, \mathrm{Al} \mathrm{LDH}$ instead of the zincian malachite precursor requires adjustment of the co-precipitation conditions [11]: a higher Al content of 30-40\% to obtain phase pure LDH material compared to typically less than $15 \%$, the use of a mixture of $\mathrm{NaOH}$ and $\mathrm{Na}_{2} \mathrm{CO}_{3}$ as precipitating agent instead of pure $\mathrm{Na}_{2} \mathrm{CO}_{3}$ to avoid formation of carbonate-richer phases like malachite, an increase of the precipitation $\mathrm{pH}$ from ca. 7 to 8 to favor formation of the hydroxide-rich LDH phase and a lower reaction temperature to avoid oxolation of $\mathrm{Cu}$ hydroxide species to $\mathrm{CuO}$ at this higher $\mathrm{pH}$. $\mathrm{Cu}, \mathrm{Zn}, \mathrm{Al} \mathrm{LDH}$ were obtained with a $\mathrm{Cu}$ content up to $50 \mathrm{~mol} \%$ [11]. At this composition the $\mathrm{Zn}: \mathrm{Al}$ ratio was close to $1: 2$ and the oxide matrix tended to form $\mathrm{ZnAl}_{2} \mathrm{O}_{4}$ [13]. The resulting catalyst showed a different microstructure than the zincian malachite-derived industrial $\mathrm{Cu} / \mathrm{ZnO} /\left(\mathrm{Al}_{2} \mathrm{O}_{3}\right)$ catalyst [11]. Due to the layered structure $\mathrm{LDH}$ precursors exhibit a platelet-like morphology. The lateral size of the $\mathrm{Cu}, \mathrm{Zn}, \mathrm{Al} \mathrm{LDH}$ platelets ranged from more than 100 down to a few tens of nanometers, while the platelet thickness was between approximately 20 and less than $5 \mathrm{~nm}$ (Fig. 4b). EDX mapping confirmed the homogenous element distribution in the LDH material. The platelet-like morphology was maintained in the final catalyst upon thermal treatment. Compared to ex-zincian malachite catalysts, a smaller average $\mathrm{Cu}$ particle size was observed in these ex-LDH platelets, which is a result of the lower total $\mathrm{Cu}$ content. However, the accessible $\mathrm{Cu}$ surface area was considerably lower, around only $10 \mathrm{~m}^{2} \mathrm{~g}^{-1}$ compared to 20 or $30 \mathrm{~m}^{2} \mathrm{~g}^{-1}$ determined for typical industrial $\mathrm{Cu} / \mathrm{Zn} / \mathrm{Al}_{2} \mathrm{O}_{3}$ catalysts using the $\mathrm{N}_{2} \mathrm{O}$ chemisorption method. This is a result of the much stronger embedment of the small metal particles in the $\mathrm{ZnAl}_{2} \mathrm{O}_{4}$ matrix. The major challenge in the preparation of such ex- $\mathrm{LDH} \mathrm{Cu} / \mathrm{ZnAl}_{2} \mathrm{O}_{4}$ catalyst is thus to optimize this "nuts-in-chocolate"-like morphology by adjusting the LDH particle size, e.g. the precursor platelet thickness, to affect the degree of embedment and increase porosity in order to find the best compromise between $\mathrm{Cu}$ metal-oxide interactions and exposed $\mathrm{SA}_{\mathrm{Cu}}$. As the LDH-derived catalysts exhibit higher thermal stability, increase in calcination temperature can be effective in this way [30]. Also a microemulsion approach for the precipitation of the precursor to "nano-cast" the platelet morphology of the LDH phase was shown to increase SA $\mathrm{Cu}$ by $75 \%$ compared to a conventionally co-precipitated ex- $\mathrm{LDH} \mathrm{Cu} / \mathrm{ZnAl}_{2} \mathrm{O}_{4}$ catalyst $(\mathrm{Cu}: \mathrm{Zn}: \mathrm{Al}=50: 17: 33)$ [12] (Tab. 1). It is interesting to note that despite the lower total $\mathrm{SA}_{\mathrm{Cu}}$, the activity per unit area was found to be higher in these systems compared to many conventional catalysts. 
a)

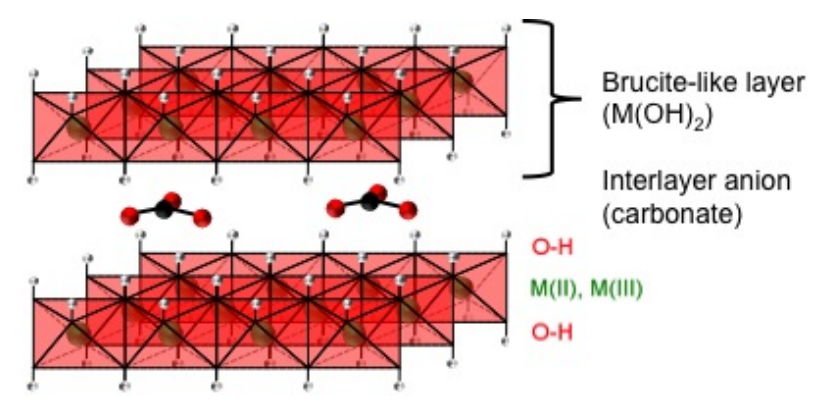

b)

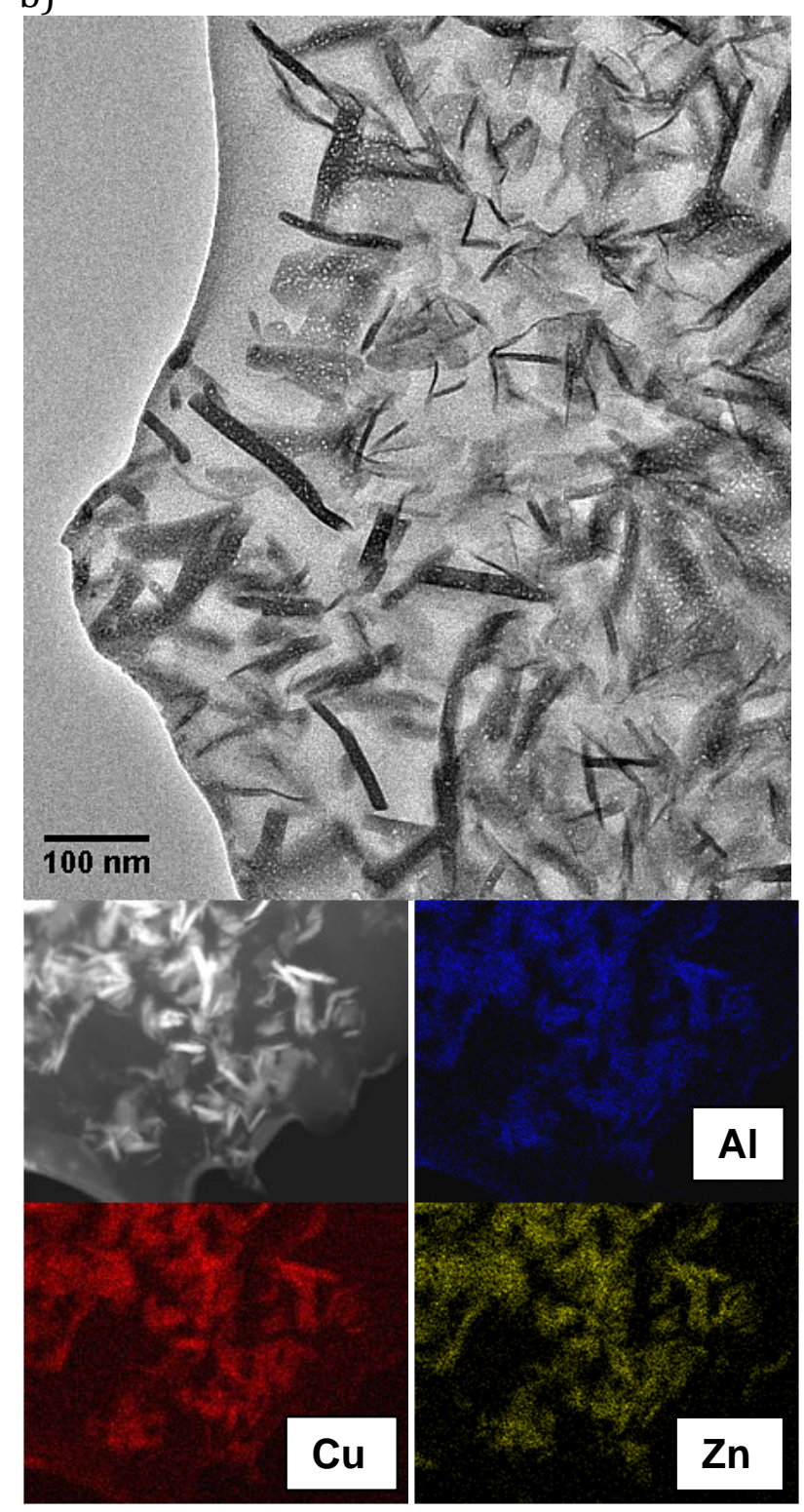

Figure 4: Idealized general representation of the LDH crystal structure (a). Cross-section TEM of an aggregate of $\mathrm{Cu}, \mathrm{Zn}, \mathrm{Al} \mathrm{LDH}$ precursor platelets (b). The microscopy sample was prepared by embedding the powder in epoxy followed by mechanical and Ar-ion beam thinning. The cross-section of many platelets appears as needles. The EDX 
mapping shows the uniform element distribution in the LDH precursor (adopted from [11]).

\subsection{Supported Ni catalysts}

The peculiar microstructure of the reduced ex-LDH catalysts with highly embedded metal nanoparticles is beneficial not only for enhanced metal-oxide interaction, but also for an improved thermal stability of the catalyst against sintering. This feature was expoited in the synthesis of highly stable Ni nanoparticles for the application in the dry reforming of methane at high temperatures. For this reaction, high temperatures are favorable, because the reaction is highly endothermic and an increase in temperature will increase the product yield. Also, the operation at high temperature thermodynamically suppresses the exothermic Boudouard side-reaction, which is to a large extent responsible for undesired carbon filament growth [31-32]. A similar synthetic approach to stabilize Ni nanoparticles at high temperatures against sintering by incorporation into a stable oxide matrix was previously also applied for Ni-containing perovskites [33] and spinels [34]. Also LDH precursors have been already applied to synthesize Ni-based catalysts for dry reforming of methane [35-36]. In our work, LDHs of the nominal composition $\mathrm{Ni}_{x} \mathrm{Mg}_{0.67-\mathrm{x}} \mathrm{Al}_{0.33}(\mathrm{OH})_{2}(\mathrm{CO})_{0.17} \cdot m \mathrm{H}_{2} \mathrm{O}$, with $0 \leq x \leq 0.5$ were synthesized by $\mathrm{pH}$-controlled co-precipitation according to the recipe introduced above for the $\mathrm{Cu}, \mathrm{Zn}, \mathrm{Al}$ system [18]. The highest $\mathrm{Ni}$ content of $50 \mathrm{~mol} \%$ (metal base) corresponds to a $55 \mathrm{wt} . \mathrm{\%} \mathrm{Ni}$ loading in the resulting catalyst. As described above for $\mathrm{Cu} / \mathrm{ZnAl}_{2} \mathrm{O}_{4}$, the $1: 2$ ratio of $\mathrm{Mg}$ and $\mathrm{Al}$ is expected to lead to spinel formation, $\mathrm{MgAl}_{2} \mathrm{O}_{4}$ - a sintering-stable ceramic compound. In addition, beneficial effects on the coking behavior of Ni catalysts have been reported on alumina, magnesia and spinel supports [37].

The characterization results show, similar to the $\mathrm{Cu}, \mathrm{Zn}, \mathrm{Al}$ case described above, that a phase pure LDH precursor with the typical platelet-like morphology was obtained. Upon calcination, the LDH structure is completely decomposed at $600{ }^{\circ} \mathrm{C}$ yielding a poorly crystalline oxide pre-catalyst. After this relatively mild calcination, no indication for segregation of individual species was found and the platelet shape of the particles was maintained. Thus, the calcination product is an amorphous, mixed $\mathrm{Ni}, \mathrm{Mg}, \mathrm{Al}$ oxide, whose 
homogenous distribution of the metal species has been largely conserved during decomposition of the LDH precursor (Fig. 5a).

After reduction of the calcined material in hydrogen at $800^{\circ} \mathrm{C}$, electron microscopy revealed that the platelet-like morphology of the $\mathrm{LDH}$ precursor is still present indicating a strong resistivity of the material against reconstructions at high temperatures (Fig 5b). In addition, bright dots can be observed in the SEM micrographs homogeneously distributed over the platelets confirming that a nanoscopic segregation of the components has taken place.
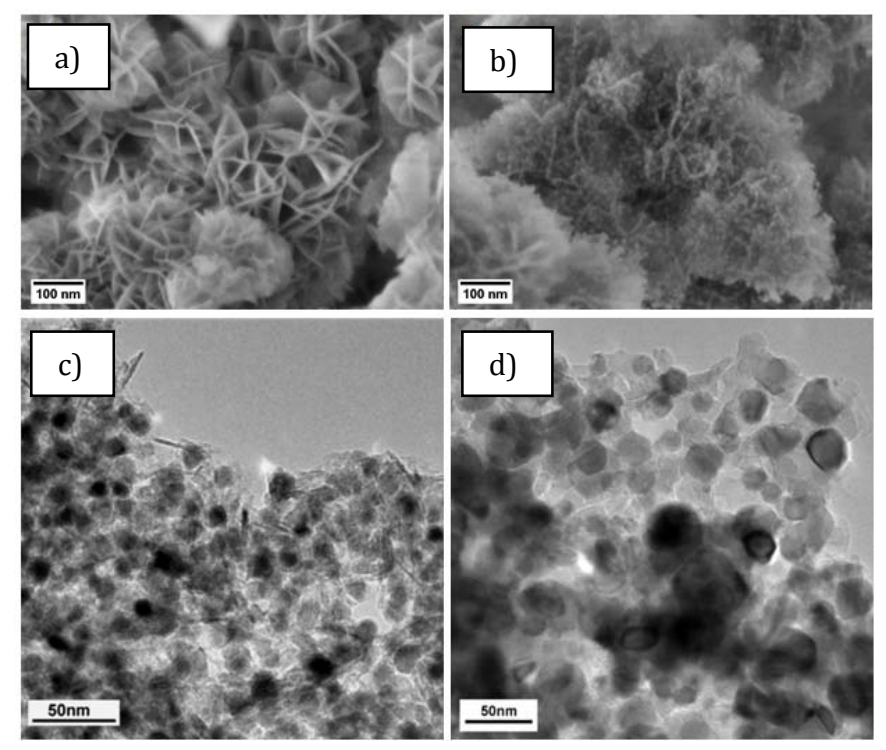

Figure 5: SEM images of the precursor material (a) and the catalyst after reduction at $800{ }^{\circ} \mathrm{C}(\mathrm{b})$ and TEM micrographs of the fresh $\mathrm{Ni} / \mathrm{MgAl}_{2} \mathrm{O}_{4}$ catalyst with 50 mol.\% $\mathrm{Ni}(x=$ $0.5 ; 55$ wt.\%) after reduction at 800 (c) and $1000{ }^{\circ} \mathrm{C}(\mathrm{d}$, adopted from [18]).

Indeed, XRD of the catalysts with $x=0.5$ clearly confirmed the presence of metallic $\mathrm{Ni}$. The oxidic component is still only poorly crystalline and no sharp peaks of spinel were detected. TEM analysis of individual platelets in the reduced material revealed an average particle size of $\mathrm{Ni}$ around $10 \mathrm{~nm}$, despite the high reduction temperature and the high overall loading of 55 wt.\% Ni (Fig. 5c). The Ni surface area was determined by hydrogen pulse chemisorption and found to be $22 \mathrm{~m}^{2} \mathrm{gcat}^{-1}$ at a BET surface area of 226 $\mathrm{m}^{2} \mathrm{~g}^{-1}$ after reduction (Tab. 1). Interestingly, at these high reduction temperatures, there was no clear effect of the Ni loading on the Ni particle size and approximately $10 \mathrm{~nm}$ were also observed for $x=0.05$. Even an increase of the reduction temperature to $900{ }^{\circ} \mathrm{C}$ did not significantly influence the Ni particle size proving the high thermal stability of 
this composite material. Only after reduction at $1000^{\circ} \mathrm{C}$, a substantial particle growth to $19 \mathrm{~nm}$ was observed (Fig. 5d, Tab. 1). Due to this highly stable microstructure, whose origin is the precursor-induced embedment of the Ni particles in the ceramic matrix, the catalyst can be employed at a reaction temperature of $900^{\circ} \mathrm{C}$ and it showed a remarkable stability over 100 hours [18]. It was shown recently that the catalyst loses its beneficial microstructure inherited from the LDH precursor upon repeated TPR-O cycles leading to an increase in Ni particle size to $21 \mathrm{~nm}$ after 21 cycles [38]. These experiments show the general limit of the precursor approaches. The composite system is only kinetically trapped in a favorable, but labile microstructure with finite stability, which was inherited by the structural and morphological properties of the precursor. As the system relaxes at higher temperatures or upon long operation time, these properties or the "chemical memory" of the catalyst might also slowly vanish.

\subsection{Supported noble metal catalysts: Palladium}

The same synthesis approach via LDH precursors can also be used for noble metals like $\mathrm{Pd}$. It is noted that $\mathrm{Pd}^{2+}$ is not easily incorporated in the $\mathrm{LDH}$ layers due to its larger ionic size compared to $\mathrm{Mg}^{2+}$, which exceeds the empirical limit of approximately $0.80 \AA$ for the incorporation into $\mathrm{LDH}$ [39]. Furthermore, $\mathrm{Pd}^{2+}$ in aqueous solutions exhibits a tendency towards four-fold square-planar coordination instead of an octahedral one as required in LDH. Therefore only small amounts of $\mathrm{Pd}^{2+}$ can be incorporated in the LDH precursor and a second bivalent cation as diluent, like $\mathrm{Mg}^{2+}$, is needed to achieve crystallization of all Pd ions in a single LDH phase. As typical loadings of noble metal catalysts are anyway lower compared to base metals for cost reasons, the limited solubility of $\mathrm{Pd}^{2+}$ in LDH is usually not a great problem.

Pd,Mg,Al LDH precursors were synthesized under slightly adjusted conditions with a Pd:Mg:Al atomic ratio of $x: 0.7-x: 0.3(0.001 \leq x \leq 0.025)$ [14]. The precursor was reduced in $5 \% \mathrm{H}_{2}$ in argon at $500{ }^{\circ} \mathrm{C}$ without prior calcination. The resulting series of $\mathrm{Pd} / \mathrm{MgO} / \mathrm{MgAl}_{2} \mathrm{O}_{4}$ catalysts has been characterized and was found to contain $\mathrm{Pd}$ nanoparticles (Fig. 6), whose size can be controlled to some extent between $<1.9$ and $3.5 \mathrm{~nm}$ by adjusting the Pd content during synthesis (Fig. 7, Tab. 1). The sample with the lowest Pd loading of 0.33 wt-\% (0.1 mol.\%, $x=0.001)$ showed a much greater $\mathrm{Pd}$ dispersion compared to those samples with Pd contents between 1.5 and 8 wt.\% (0.5 - 
2.5 mol. $\%, 0.005 \leq \mathrm{x} \leq 0.025$ ) making this series of catalysts a suitable materials basis for studying particle size effects in hydrocarbon activation [40].

a)

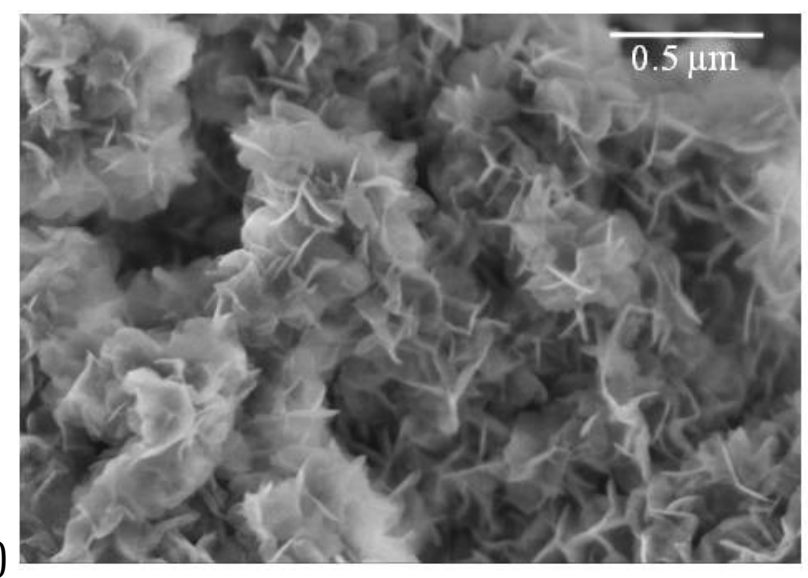

b)

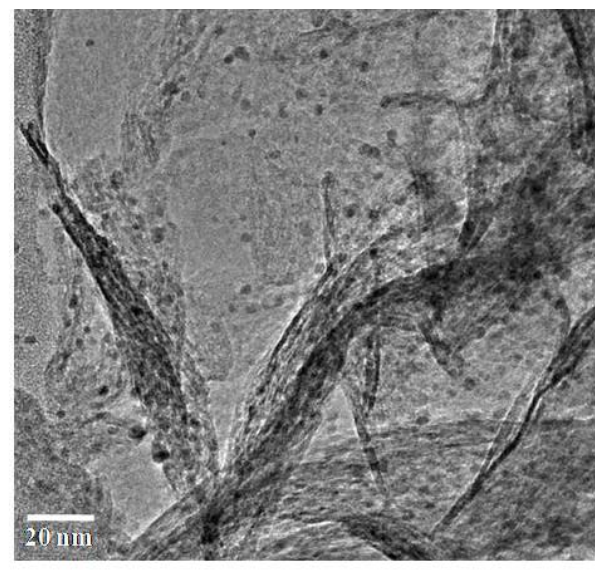

Fig. 6: SEM of the typical LDH morphology of the Pd,Mg,Al precursor (a) and TEM of the catalyst obtained after reduction with small Pd nanoparticles (dark dots) formed throughout the oxide platelets (adopted from [14]).
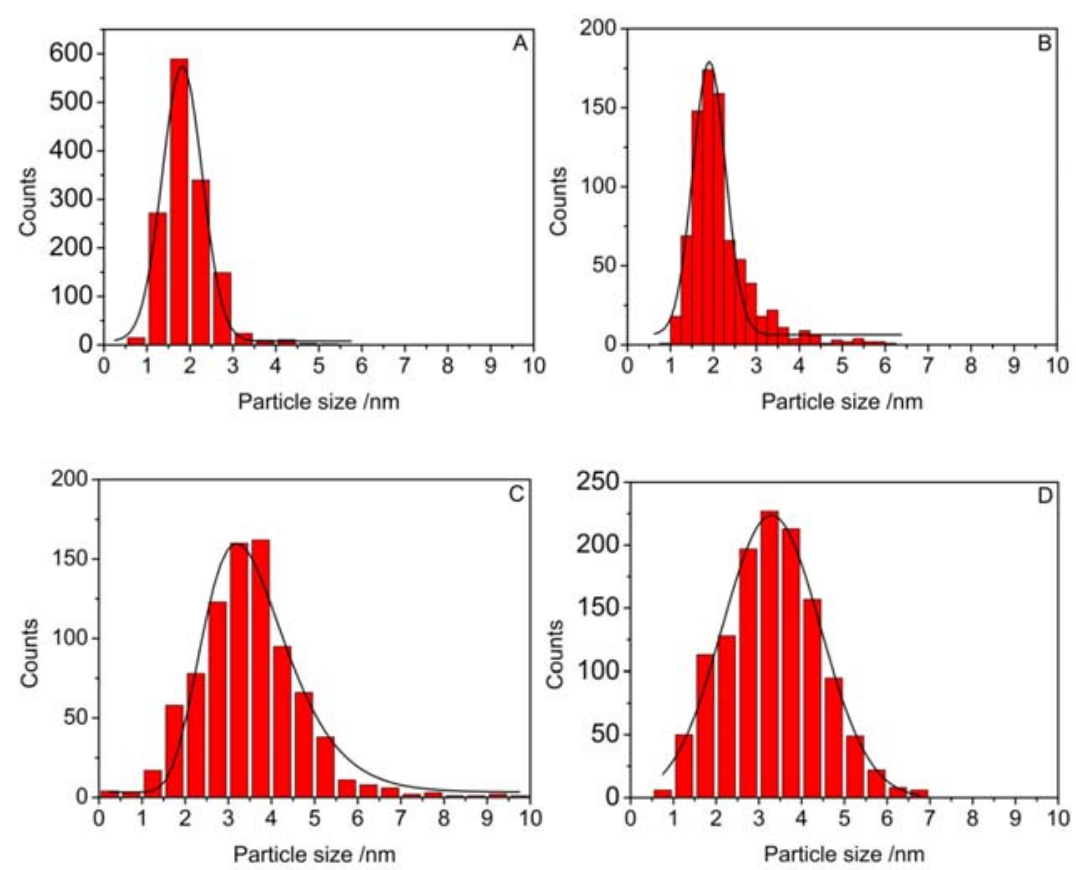

Fig. 7: Dependency of the Pd nanoparticle size distribution on the loading of $\mathrm{Pd}^{2+}$ in the $\mathrm{LDH}$ precursor after reduction at $550{ }^{\circ} \mathrm{C}$ (A: 0.5\%; B: 1.0\%; C: 1.5\%; D: 2.5\%, given as mol\% of metal cation subsititon in the LDH, taken from [14]).

The series of LDH-derived Pd catalysts was studied in methane chemisorption. The adsorption capacity of these catalysts was generally very high compared to Pd samples prepared by other methods [14]. In particular, an extraordinary high capacity was observed for the sample with the lowest loading of $0.33 \mathrm{wt} . \%(0.1 \mathrm{~mol} . \%, x=0.001)$. Its 
particles displayed a significantly higher intrinsic methane adsorption capacity than other members of the series, whose intrinsic capacities were comparable (Fig. 8). This observation indicates the existence of a size effect in Pd nanoparticles for the adsorption of methane and confirms the structure-sensitivty of this reaction. The ex-LDH samples have shown that a critical Pd cluster size below $1.9 \mathrm{~nm}$ is required for the enhanced adsorption to take place.

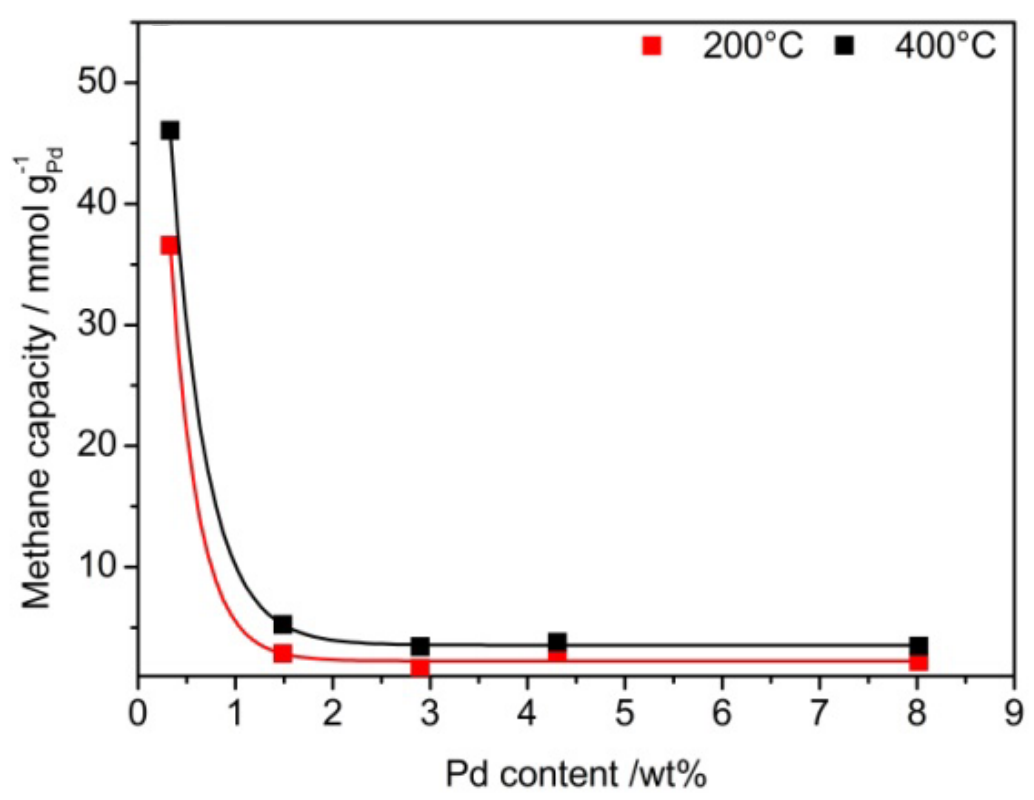

Fig. 8: Pd mass-normalized methane chemisorption capacity at 200 and $400{ }^{\circ} \mathrm{C}$ of the exLDH Pd catalysts as a function of Pd loading. The four samples with high loading correspond to the catalysts shown in Figure 7, the Pd particles of the lowest loaded catalysts were too small to be characterized by TEM (taken from [14])

\subsection{Supported intermetallic catalysts: $P d_{2} G a$}

Ordered intermetallic compounds (IMCs) are discussed as interesting catalytic materials for many reactions [41]. For example, in the IMC $\mathrm{Pd}_{2} \mathrm{Ga}$ was investigated in selective hydrogenation of acetylene [42]. For catalytic applications, such IMCs should be present in form of nanoparticles supported on a high surface area material [43].

A feasible synthesis route to supported $\mathrm{Pd}_{2} \mathrm{Ga}$ nanoparticles is the above-described approach through a co-precipitated $\mathrm{Pd}, \mathrm{Mg}$,Ga LDH precursor to evenly distribute the constituent elements of the intermetallic compound as well as of the support in a single precursor phase [15]. Similar to the monometallic Pd catalysts with $\mathrm{Al}$ instead of Ga 
introduced in the previous section, Pd nanoparticles are formed in the initial reduction step from such a precursor under reducing conditions. Upon further increase of the reduction temperature, partial reduction of the gallium species by spillover of atomic hydrogen from the metallic Pd surface [44] sets in leading to the formation of the IMC [45], while unreduced components of the precursor constitute the oxide support. Like this supported and dispersed IMCs are generated by reaction between noble metal and the reducible oxide support in a feasible and reproducible manner. The homogeneous distribution and the low amount of Pd in the LDH precursor help the formation of very small and reactive $\mathrm{Pd}^{0}$ particles [14]. The single phase LDH precursor is expected to favor the formation of uniform and nano-sized $\mathrm{Pd}_{2} \mathrm{Ga}$ IMC because it provides a homogenous microstructure concerning Pd particle size and Pd metal-oxide interactions.

A Pd,Mg,Ga LDH precursor with $x=0.025$ (molar ratio 2.5:67.5:30) was synthesized by controlled co-precipitation at $\mathrm{pH}=8.5$ and $55^{\circ} \mathrm{C}$ by co-feeding appropriate amounts of mixed aqueous metal nitrate and sodium carbonate solution as precipitating agent. The precursor was reduced in $5 \% \mathrm{H}_{2}$ in argon at $550{ }^{\circ} \mathrm{C}$ to obtain the supported $\mathrm{Pd}_{2} \mathrm{Ga}$ intermetallic compound. The reduction process of the Ga-species was monitored by insitu Pd K-edge XANES (Fig. 9) showing the formation of mono-metallic Pd at low and IMC formation at higher reduction temperature. High resolution TEM of the reduced catalysts also shows that the $\mathrm{Pd}_{2} \mathrm{Ga}$ phase was successfully formed within the oxidic platelets and that the average particle size was below $5 \mathrm{~nm}$ (Fig. 10, Tab. 1).

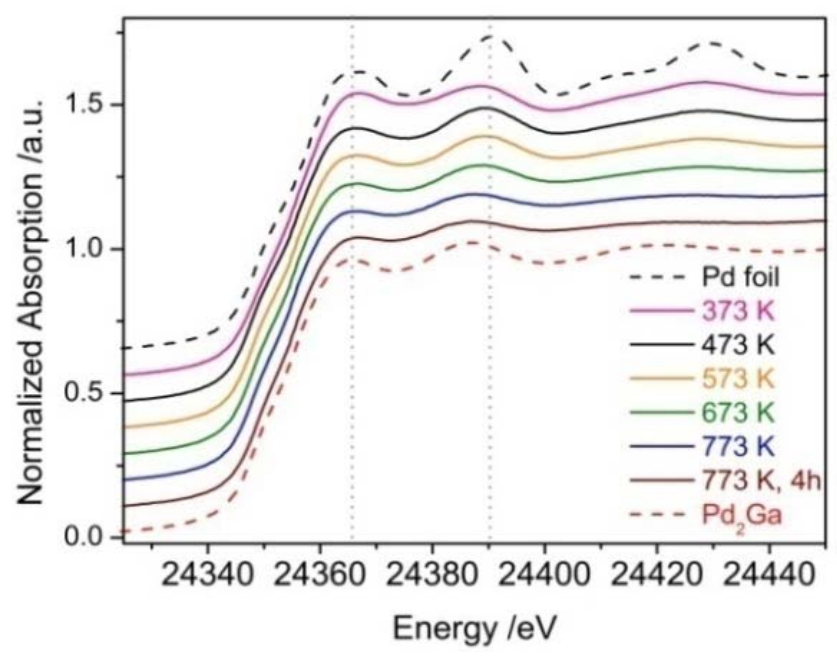

Fig. 9: IMC formation from $\mathrm{Pd}, \mathrm{Mg}, \mathrm{Ga} \mathrm{LDH}$ precursors upon reduction monitored by insiteu XANES (taken from [17]) 

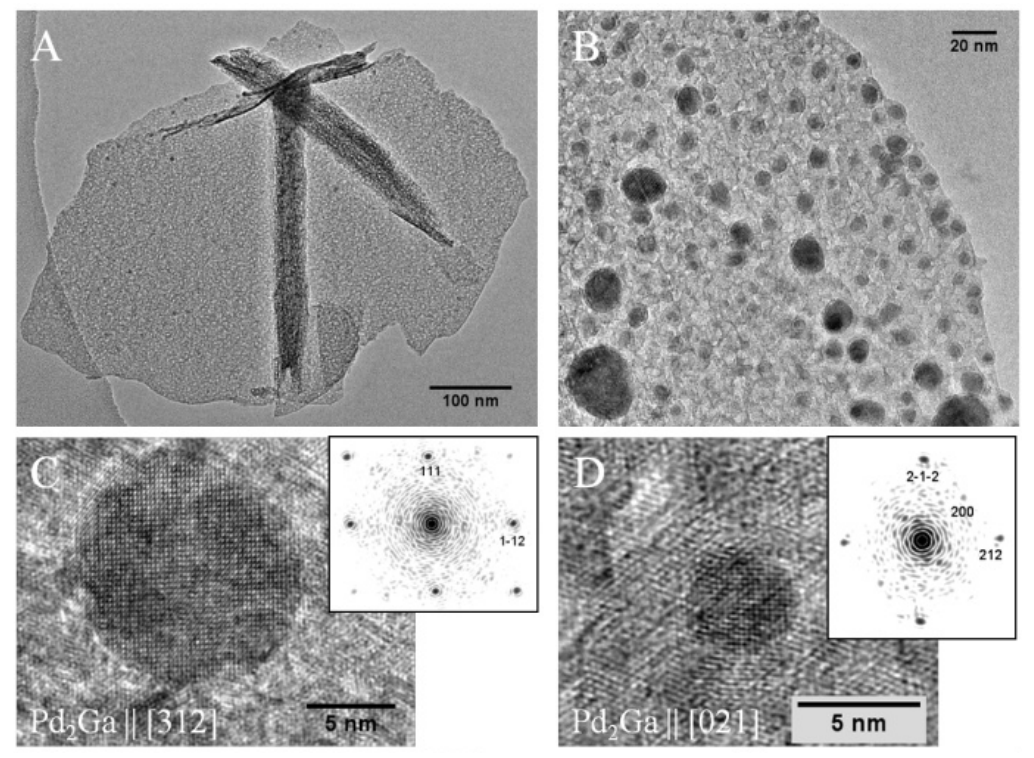

Fig. 10: TEM and HRTEM images of the reduced Pd,Mg,Ga LDH precursor showing the platelet morphology (a), the presence of metal nanoparticles (b) and evidence for the formation of the $\mathrm{Pd}_{2} \mathrm{Ga}$ phase (c,d, taken from [17])

\section{Conclusion}

Recent examples of synthesis of supported catalysts derived from LDH precursors and their applications have been described. An overview and selected properties are summarized in Table 1. This precursor material is very versatile and can lead to highly loaded base metal as well as to mono- and bi-metallic highly dispersed noble metal catalysts with an increased thermal stability. The general steps of this synthesis route are analogous to those successfully applied in the industrial synthesis of methanol synthesis catalysts. Co-precipitation leads to well-defined and crystalline precursor compounds with a mixed cationic lattice that contains all components of the final catalyst. The anions are thermally decomposed to give the mixed oxides and the noblest components finally segregate on a nano-metric level to yield uniform metal/intermetallic nanoparticles. 
Tab. 1: Overview on the LDH-derived catalysts reviewed in this article with selected properties and the reaction systems applied.

\begin{tabular}{|c|c|c|c|c|c|}
\hline Cations & $\begin{array}{l}\text { Composition } \\
\text { / mol.\% }\end{array}$ & $\begin{array}{l}\mathrm{T}_{\text {Reduction }} \\
/{ }^{\circ} \mathrm{C}\end{array}$ & $\begin{array}{l}\mathrm{SA}_{\text {Metal }} / \\
\mathrm{m}^{2} \mathrm{~g}_{\text {cat }^{-1}} \text {, or } \\
\text { dispersion }\end{array}$ & $\begin{array}{l}\text { Metal particle } \\
\text { size }^{\mathrm{b}} / \mathrm{nm}\end{array}$ & $\begin{array}{l}\text { Reactionc, } \\
\text { remarks } \\
\text { [reference] }\end{array}$ \\
\hline \multirow[t]{2}{*}{$\mathrm{Cu}, \mathrm{Zn}, \mathrm{Al}$} & \multirow[t]{2}{*}{$50 / 17 / 33$} & \multirow[t]{2}{*}{300} & 8.3 & 7.7 & $\begin{array}{l}\text { MSR [12], MS } \\
{[46]}\end{array}$ \\
\hline & & & 13.8 & 7.8 & $\begin{array}{l}\text { MSR, micro- } \\
\text { emulsion } \\
{[12]}\end{array}$ \\
\hline \multirow[t]{4}{*}{$\mathrm{Ni}, \mathrm{Mg}, \mathrm{Al}$} & \multirow[t]{3}{*}{$50 / 17 / 33$} & 800 & 22 & 10.4 & \multirow{4}{*}{$\begin{array}{l}\text { DRM } \\
{[18,47]}\end{array}$} \\
\hline & & 900 & 19 & 8.9 & \\
\hline & & 1000 & 6 & 19.4 & \\
\hline & $5 / 62 / 33$ & 1000 & 3 & 9.3 & \\
\hline \multirow[t]{5}{*}{$\mathrm{Pd}, \mathrm{Mg}, \mathrm{Al}$} & $0.1 / 69.9 / 30$ & \multirow[t]{6}{*}{550} & $67 \%$ & n.d. & \multirow{5}{*}{$\begin{array}{l}\mathrm{CH}_{4} \text { chem. } \\
{[14]}\end{array}$} \\
\hline & $0.5 / 69.5 / 30$ & & $17 \%$ & 1.9 & \\
\hline & $1.0 / 69.0 / 30$ & & $25 \%$ & 2.2 & \\
\hline & $1.5 / 68.5 / 30$ & & $14 \%$ & 3.5 & \\
\hline & $2.5 / 67.5 / 30$ & & $16 \%$ & 3.3 & \\
\hline $\mathrm{Pd}, \mathrm{Mg}, \mathrm{Ga}$ & $2.5 / 67.5 / 30$ & & n.d. & $4.8\left(\mathrm{Pd}_{2} \mathrm{Ga}\right)$ & $\begin{array}{l}\text { Sel. Hydr. } \\
{[15,17]}\end{array}$ \\
\hline
\end{tabular}

a determined using $\mathrm{N}_{2} \mathrm{O}(\mathrm{Cu}), \mathrm{H}_{2}(\mathrm{Ni})$ or $\mathrm{CO}(\mathrm{Pd})$ as probe molecules.

b determined by TEM.

${ }^{c}$ MSR = methanol steam reforming, MS = methanol synthesis, DRM = dry reforming of methanol, $\mathrm{CH} 4 \mathrm{chem} .=$ methane chemisorption, Sel. Hydr. = selective hydrogenation of acetylene.

\section{Acknowledgements}

The thorough experimental work of my group members at the Fritz-Haber-Institute is greatly acknowledged. I also thank Robert Schlögl for his continuous support and for fruitful discussions during my time in Berlin. 


\section{References}

1. Schüth, F., M. Hesse, and K.K. Unger, Precipitation and Coprecipitation, in Handbook of Heterogeneous Catalysis. 2008, Wiley-VCH Verlag GmbH \& Co. KGaA.

2. Cavani, F., F. Trifirò, and A. Vaccari, Hydrotalcite-type anionic clays: Preparation, properties and applications. Catalysis Today, 1991.11(2): p. 173-301.

3. Synthesis of Solid Catalysts, ed. K.P.d. Jong. 2009: Wiley-VCH Verlag GmbH \& Co. KGaA. I-XX.

4. Waller, D., et al., Copper-zinc oxide catalysts. Activity in relation to precursor structure and morphology. Faraday Discussions of the Chemical Society, 1989. 87: p. 107-120.

5. Baltes, C., S. Vukojevic, and F. Schuth, Correlations between synthesis, precursor, and catalyst structure and activity of a large set of $\mathrm{CuO} / \mathrm{ZnO} / \mathrm{Al} 2 \mathrm{O} 3$ catalysts for methanol synthesis. Journal of Catalysis, 2008. 258(2): p. 334-344.

6. Li, J.L. and T. Inui, Characterization of precursors of methanol synthesis catalysts, copper zinc aluminum oxides, precipitated at different $p H s$ and temperatures. Applied Catalysis a-General, 1996. 137(1): p. 105-117.

7. Behrens, M. and R. Schlögl, How to Prepare a Good Cu/ZnO Catalyst or the Role of Solid State Chemistry for the Synthesis of Nanostructured Catalysts. Zeitschrift für anorganische und allgemeine Chemie, 2013.639(15): p. 2683-2695.

8. Behrens, M., Methanol Steam Reforming, in Catalysis for alternative energy generation (eds: L. Guczi, A. Erdohelyi), M. Armbruster, Editor. 2012, Springer.

9. Behrens, M. and E. Kunkes, Methanol Chemistry, in Chemical Energy Storage, R. Schlögl, Editor. 2012, Walter de Gruyter: Berlin. p. 413-442.

10. Behrens, M., et al., Knowledge-based development of a nitrate-free synthesis route for $\mathrm{Cu} / \mathrm{ZnO}$ methanol synthesis catalysts via formate precursors. Chemical Communications, 2011. 47(6): p. 1701-1703.

11. Behrens, M., et al., Phase-Pure Cu,Zn,Al Hydrotalcite-like Materials as Precursors for Copper rich Cu/ZnO/Al2O3 Catalysts. Chemistry of Materials, 2009. 22(2): p. 386-397.

12. Kuhl, S., et al., $\mathrm{Cu}, \mathrm{Zn}, \mathrm{Al}$ layered double hydroxides as precursors for copper catalysts in methanol steam reforming - $p H$-controlled synthesis by microemulsion technique. Journal of Materials Chemistry, 2012. 22(19): p. 9632-9638.

13. Kühl, S., et al., Cu-Based Catalyst Resulting from a Cu,Zn,Al Hydrotalcite-Like Compound: A Microstructural, Thermoanalytical, and In Situ XAS Study. Chemistry - A European Journal, 2014. 20(13): p. 3782-3792.

14. Ota, A., et al., Particle size effect in methane activation over supported palladium nanoparticles. Applied Catalysis A: General, 2013. 452(0): p. 203-213.

15. Ota, A., et al., Intermetallic Compound Pd2Ga as a Selective Catalyst for the SemiHydrogenation of Acetylene: From Model to High Performance Systemst. The Journal of Physical Chemistry C, 2010. 115(4): p. 1368-1374.

16. Ota, A., et al., Comparative study of hydrotalcite-derived supported Pd2Ga and PdZn intermetallic nanoparticles as methanol synthesis and methanol steam reforming catalysts. Journal of Catalysis, 2012. 293(0): p. 27-38.

17. Ota, A., et al., Dynamic Surface Processes of Nanostructured Pd2Ga Catalysts Derived from Hydrotalcite-Like Precursors. ACS Catalysis, 2014: p. 2048-2059.

18. Mette, K., et al., Stable Performance of Ni Catalysts in the Dry Reforming of Methane at High Temperatures for the Efficient Conversion of CO2 into Syngas.

ChemCatChem, 2014. 6(1): p. 100-104. 
19. Behrens, M., et al., The Active Site of Methanol Synthesis over Cu/ZnO/Al2O3 Industrial Catalysts. Science, 2012. 336(6083): p. 893-897.

20. Gunter, M.M., et al., Implication of the microstructure of binary Cu/ZnO catalysts for their catalytic activity in methanol synthesis. Catalysis Letters, 2001. 71(1-2): p. 37-44.

21. Fujitani, T., et al., The kinetics and mechanism of methanol synthesis by hydrogenation of CO2 over a Zn-deposited Cu(111) surface. Surface Science, 1997. 383(2-3): p. 285-298.

22. Nakamura, J., Y. Choi, and T. Fujitani, On the issue of the active site and the role of $\mathrm{ZnO}$ in $\mathrm{Cu} / \mathrm{ZnO}$ methanol synthesis catalysts. Topics in Catalysis, 2003. 22(3-4): p. 277-285.

23. Zander, S., et al., The Role of the Oxide Component in the Development of Copper Composite Catalysts for Methanol Synthesis. Angewandte Chemie International Edition, 2013. 52(25): p. 6536-6540.

24. Behrens, M., et al., Understanding the complexity of a catalyst synthesis: Coprecipitation of mixed $\mathrm{Cu}, \mathrm{Zn}, \mathrm{Al}$ hydroxycarbonate precursors for $\mathrm{Cu} / \mathrm{ZnO} / \mathrm{Al}(2) \mathrm{O}(3)$ catalysts investigated by titration experiments. Applied Catalysis a-General, 2011. 392(1-2): p. 93-102.

25. Kniep, B.L., et al., Rational design of nanostructured copper-zinc oxide catalysts for the steam reforming of methanol. Angewandte Chemie-International Edition, 2004. 43(1): p. 112-115.

26. Zander, S., B. Seidlhofer, and M. Behrens, In situ EDXRD study of the chemistry of aging of co-precipitated mixed $\mathrm{Cu}, \mathrm{Zn}$ hydroxycarbonates - consequences for the preparation of $\mathrm{Cu} / \mathrm{ZnO}$ catalysts. Dalton Transactions, 2012. 41(43): p. 1341313422.

27. Behrens, M. and F. Girgsdies, Structural Effects of Cu/Zn Substitution in the Malachite-Rosasite System Zeitschrift für anorganische und allgemeine Chemie, 2010. 636(6): p. 919-927.

28. Behrens, M., Meso- and nano-structuring of industrial $\mathrm{Cu} / \mathrm{ZnO} /(\operatorname{Al}(2) \mathrm{O}(3))$ catalysts. Journal of Catalysis, 2009. 267(1): p. 24-29.

29. Behrens, M., et al., Performance Improvement of Nanocatalysts by PromoterInduced Defects in the Support Material: Methanol Synthesis over Cu/ZnO:Al. Journal of the American Chemical Society, 2013. 135(16): p. 6061-6068.

30. Tang, Y., et al., High-performance HTLcs-derived CuZnAl catalysts for hydrogen production via methanol steam reforming. AIChE Journal, 2009. 55(5): p. 12171228.

31. Swaan, H.M., et al., Deactivation of supported nickel catalysts during the reforming of methane by carbon dioxide. Catalysis Today, 1994. 21(2-3): p. 571-578.

32. Tsipouriari, V.A., et al., Reforming of methane with carbon dioxide to synthesis gas over supported Rh catalysts. Catalysis Today, 1994. 21(2-3): p. 579-587.

33. Choudhary, V.R., B.S. Uphade, and A.A. Belhekar, Oxidative Conversion of Methane to Syngas over LaNiO3Perovskite with or without Simultaneous Steam and CO2Reforming Reactions: Influence of Partial Substitution of La and Ni. Journal of Catalysis, 1996. 163(2): p. 312-318.

34. Guo, J., et al., Dry reforming of methane over nickel catalysts supported on magnesium aluminate spinels. Applied Catalysis A: General, 2004. 273(1-2): p. 75-82.

35. Tsyganok, A.I., et al., Dry reforming of methane over catalysts derived from nickelcontaining Mg-Al layered double hydroxides. Journal of Catalysis, 2003. 213(2): p. 191-203. 
36. Perez-Lopez, O.W., et al., Effect of composition and thermal pretreatment on properties of $\mathrm{Ni}-\mathrm{Mg}$-Al catalysts for $\mathrm{CO} 2$ reforming of methane. Applied Catalysis A: General, 2006. 303(2): p. 234-244.

37. Chen, Y.-g. and J. Ren, Conversion of methane and carbon dioxide into synthesis gas over alumina-supported nickel catalysts. Effect of Ni-Al2O3 interactions. Catalysis Letters, 1994. 29(1-2): p. 39-48.

38. Mette, K., et al., Redox Dynamics of Ni Catalysts in CO2 Reforming of Methane. Catalysis Today, 2014. submitted.

39. De Roy, A., Lamellar Double Hydroxides. Molecular Crystals and Liquid Crystals Science and Technology. Section A. Molecular Crystals and Liquid Crystals, 1998. 311: p. 173 -193.

40. Klier, K., J.S. Hess, and R.G. Herman, Structure sensitivity of methane dissociation on palladium single crystal surfaces. The Journal of Chemical Physics, 1997. 107(10): p. 4033-4043.

41. Studt, F., et al., Discovery of a Ni-Ga catalyst for carbon dioxide reduction to methanol. Nat Chem, 2014. 6(4): p. 320-324.

42. Armbrüster, M., et al., Pd-Ga Intermetallic Compounds as Highly Selective Semihydrogenation Catalysts. Journal of the American Chemical Society, 2010. 132(42): p. 14745-14747.

43. He, Y., et al., Partial hydrogenation of acetylene using highly stable dispersed bimetallic Pd-Ga/MgO-Al2O3 catalyst. Journal of Catalysis, 2014. 309(0): p. 166173.

44. Collins, S.E., et al., Gallium-Hydrogen Bond Formation on Gallium and GalliumPalladium Silica-Supported Catalysts. Journal of Catalysis, 2002. 211(1): p. 252264.

45. Penner, S., et al., Pd/Ga203 methanol steam reforming catalysts: Part I. Morphology, composition and structural aspects. Applied Catalysis A: General, 2009. 358(2): p. 193-202.

46. Kühl, S., et al., Ternary and quaternary Cr or Ga-containg ex-LDH catalysts influence of the additional oxides onto the microstructure and activity of $\mathrm{Cu} / \mathrm{ZnAl20} 4$ catalysts. Catalysis Today, 2014. submitted.

47. Düdder, H., et al., Role of carbonaceous deposits in the activity and stability of Nibased catalysts applied in the dry reforming of methane. Catal. Sci. Technol., 2014. accepted. 